\title{
Author Correction: Molecular basis of mycobacterial survival in macrophages
}

\author{
Jane Atesoh Awuh ${ }^{1}$ Trude Helen Flo ${ }^{1,2}$ 俩
}

Published online: 11 October 2017

(C) Springer International Publishing AG 2017

Author Correction: Cell Mol Life Sci (2017)

74:1625-1648

DOI 10.1007/s00018-016-2422-8

One of the author affiliations was missed to include in the original publication. The correct information is given below:

1 Centre of Molecular Inflammation Research, Department of Cancer Research and Molecular Medicine, Norwegian University of Science and Technology, Trondheim, Norway.

2 Centre for Molecular Medicine Norway, Nordic EMBL Partnership, University of Oslo and Oslo University Hospital, Oslo, Norway.

The online version of the original article can be found under doi:10.1007/s00018-016-2422-8.

Trude Helen Flo

trude.flo@ntnu.no

Jane Atesoh Awuh

jane.awuh@ntnu.no

1 Centre of Molecular Inflammation Research, Department of Cancer Research and Molecular Medicine, Norwegian University of Science and Technology, PB 8905,

7491 Trondheim, Norway

2 Centre for Molecular Medicine Norway, Nordic EMBL Partnership, University of Oslo and Oslo University Hospital, Oslo, Norway 